\title{
Frequency of Medical Co-Morbidities in Oral Surgery, Prosthodontic and Orthodontic Patients
}

\author{
Hafiz Nasir Mahmood ${ }^{1}$ \\ BDS \\ Muhammad Waseem Ullah Khan ${ }^{2}$ \\ BDS, FCPS \\ Muhammad Azeem ${ }^{3}$ \\ BDS, FCPS \\ Sabiha Naeem ${ }^{4}$ \\ BDS \\ Asif Ali Shah ${ }^{5}$ \\ Muhammad Mudassar Saleem ${ }^{6}$ \\ BDS, MSc, MDS \\ BDS, FCPS
}

OBJECTIVE: Co-morbidity is a medical condition accompanied to the primary condition for which patient is seeking medical or dental care. To determine the frequency of medical co-morbid conditions in dental patients.

METHODOLOGY: After obtaining informed consent, a comprehensive predesigned history form was implemented to record patient's medical conditions. Different variables recorded for each participant were age, gender and history of medical co-morbid conditions including diabetes mellitus, hypertension, ischemic heart diseases, renal disorders, typhoid, thyroid disorder, degenerative joint disorder, asthma, hepatitis B, hepatitis C, hepatitis A and E, HIV and tuberculosis.

RESULTS: In this study, hypertension accounted for $9.5 \%$ in total number of patients followed by degenerative joint disorders and hepatitis C with the same frequency of 5.2\%. Diabetes mellitus and hepatitis B accounted for $3.4 \%$ of the patients CONCLUSION: This study concludes that presentation of medically compromised patients in dentistry is inevitable. KEY WORDS: Orthodontics; Prosthodontics; Oral surgery; Medical co-morbidities.

HOW TO CITE: Mahmood HN, Khan MWU, Azeem M, Naeem S, Shah AA, Saleem MM. Frequency of medical co-morbidities in oral surgery, prosthodontic and orthodontic patients. J Pak Dent Assoc 2020;29(1):38-41.

DOI: https://doi.org/10.25301/JPDA.291.38

Received: 16 July 2019, Accepted: 06 December 2019

\section{INTRODUCTION}

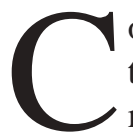
o-morbidity is a medical condition accompanied to the primary condition for which patient is seeking medical or dental care. ${ }^{1}$ Dental patients may possess various comorbidities to whom they are not aware and just appear as healthy individuals or they may have compromised quality of life due to chronic illness. Patients, on several medications for their systemic diseases can directly or indirectly have impact on dental treatment. ${ }^{2,3}$ Every dentist

1. SR, Department of Oral \& Maxillofacial Surgery, KEMU/Mayo Hospital, Lahore.

2. Assistant Professor, Department of Prosthodontics, de'Montmorency College of Dentistry, Lahore, Pakistan.

3. Assistant Professor, Department of Orthodontics, de'Montmorency College of Dentistry, Lahore, Pakistan.

4. PGR, Department of Prosthodontics, de'Montmorency College of Dentistry, Lahore, Pakistan.

5. Principal \& Professor, Department of Prosthodontics, Dental Section Rashid Latif Medical \& Dental College, Lahore, Pakistan.

6. Assistant Professor, Department of Oral \& Maxillofacial Surgery, IMDC, Islamabad, Pakistan.

Corresponding author: “Dr. Muhammad Azeem” < dental.concepts@ hotmail.com> must have necessary skills to distinguish these co-morbid medical conditions which are related to their dental treatment. ${ }^{4}$

People usually do not find any relation between their systemic and dental health, so they are reluctant to report their past medical history. Old age group demands dental treatment with their co-morbid conditions and sometimes consultation with their physician becomes mandatory. Most frequently reported medical co-morbid conditions are diabetes, chronic bronchitis, cardiovascular diseases, hypertension and arthritis. ${ }^{2-4}$ As oral care is particularly important to the general health of elderly patient so, a detailed medical historyis a preventive tool to ascertain the health care of patients by avoiding any medical emergency in dental practices. ${ }^{5-7}$

A dental professional is obliged to have a command on various factors in relation to the co-morbid conditions when treating a patient. Those factors are: patient positioning on dental chair; duration and time span for the dental appointment; selection of particular type of anesthesia, 
control of pain, anxiety and bleeding; management of syncope, hyperventilation syndrome, local anesthetic intoxication, hypoglycemia,allergies, asthma, myocardial infarction and stroke etc. ${ }^{8}$ As body is a whole oral healthsystemic health connection, therefore a blended approach to practice an integral dentistry will achieve better results. In the literature, self-administered questionnaires like Medical Risk-Related History (MRRH) ${ }^{4}$ or modified American Society of Anesthesiology (ASA) risk score ${ }^{9}$, were designed to evaluate the health status of patients.

Various studies have been conduced internationally and locally so far on the topic of prevalence of medical co-morbid conditions in dental patients, ${ }^{10-13}$ but no study conducted so far on the topic of frequency of medical co-morbid conditions in dental patients visiting oral surgery, prosthodontic and orthodontic departments. This will help in generation of dental speciality based data.

Every dentistry centre should be ready to counter any medical emergency. This preparation would include training of all the staff, training and knowledge of dental experts, and presence of emergency drugs and equipment. Following this rationale, the main objective of this study was to determine the frequency of medical co-morbid conditions in dental patients visiting oral surgery, prosthodontic and orthodontic departments.

\section{METHODOLOGY}

This study was conducted with an aim to find out the frequency of medical co-morbid conditions in dental patients. Patients attending outpatient department of our dental institute were included in the study. After obtaining informed consent from the patient, a comprehensive predesigned history from was utilized by one dental expert to record patient's medical conditions. Estimated sample size was 450 patients, based on a type I error probability (0.01) and $90 \%$ power of test, using previously conducted study, as a guide. ${ }^{9}$ The total sample size was 464 patients and duration of study was one year i.e. from 1.1.2018 to 1.1.2019.

Different variables recorded for each participant were age, gender and history of medical co-morbid conditions including diabetes mellitus, hypertension, ischemic heart diseases, renal disorders, typhoid, thyroid disorder, degenerative joint disorder, asthma, hepatitis B, hepatitis C, hepatitis A and E, HIV and tuberculosis.

\section{STATISTICAL ANALYSIS}

Data was analyzed using SPSS software. Chi square test was used to assess statistical significance in the frequency of medical conditions $(\mathrm{P}<0.05)$.

\section{RESULTS}

Data of 464 patients was included in this study. 152 patients out of 464 i.e. (32.8\%) had a history of medical co-morbidity in addition to their presenting complaint. Age of these patients ranged from 18-75 years with mean age of 45.08 with $\mathrm{SD} \pm 13.9$ years. Patients in 4 th and 5 th decade were mainly afflicted with medical co-morbidities (52.6\%). 112 patients $(73.7 \%)$ were male and 40 patients $(26.3 \%)$ were female.

In this study, hypertension was reported with highest frequency of $9.5 \%$ in total number of patients followed by degenerative joint disorders and hepatitis $\mathrm{C}$ with the same frequency of $5.2 \%$. Diabetes mellitus andhepatitis B accounted for $3.4 \%$ of the patients (Table 1). Frequency distribution of co-morbidities is graphically represented in Fig 1.

There were some patients with more than one co-morbidities $(7.8 \%)$. Within the strata of medically compromised individuals, highest frequency reported for hypertension was $28.9 \%$ followed by degenerative joint

Table 1: Frequency of Medical Co-Morbidities

\begin{tabular}{|l|c|c|}
\hline Medical co-morbidities & No. of Patients & Frequency in \%age \\
\hline Hypertension & 44 & 9.5 \\
\hline Degenerative joint disorder & 24 & 5.2 \\
\hline Hepatitis C & 24 & 5.2 \\
\hline Diabetes Mellitus & 16 & 3.4 \\
\hline Hepatitis B & 16 & 3.4 \\
\hline Hepatitis A\& E & 4 & 0.9 \\
\hline HIV & 4 & 0.9 \\
\hline Asthma & 4 & 0.9 \\
\hline Ischemic heart disease & 4 & 0.9 \\
\hline Renal disease & 4 & 0.9 \\
\hline Thyroid disorder & 4 & 0.9 \\
\hline Typhoid & 4 & 0.9 \\
\hline
\end{tabular}

Figure 1: Graphical Representation of Frequency Distribution of Co-Morbidities

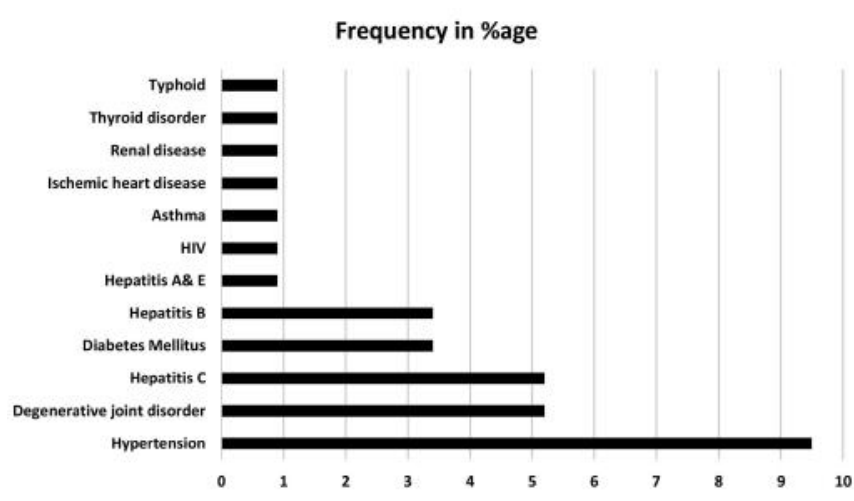

disorders and hepatitis $\mathrm{C}$ with frequency of $15.8 \%$. Diabetes mellitus and hepatitis B reported with frequency of $10.5 \%$. Hypertension and diabetes mellitus reported with higher 
frequency in males while degenerative joint disorder in females.

\section{DISCUSSION}

Oral health problems may be a manifestation of systemic disease or may significantly influence the health of entire body. Conventional dental treatment alone will not take care of systemic issues. Dentists must have understanding of medical co-morbidities so, they would be able to handle related complications and emergency situations. ${ }^{2}$ Before starting any dental procedure, a thorough history and physical examination is essential to assess the physical and mental health status of the patient. ${ }^{2,4}$ In medical technology, modern advancements have increased the life expectancy of patients. Non-invasive procedures are recommended for medically ill dental patients. ${ }^{4}$ Dental professionals can provide good oral care if they are aware of special needs of medically compromised patients. Short and early morning dental appointments must be scheduled for the patients suffering from cardiovascular diseases, arthritis, diabetes mellitus, chronic obstructive pulmonary disease. Supine position is not comfortable for dyspneic patients while dental treattment. ${ }^{8}$ When treating the dental patients with blood disorders, an eye on patient's tendency to bleed is mandatory. A proper plan is needed to implement preventive dental care to the patients undergoing radiotherapy, chemotherapy, dialysis and anti-coagulation therapy. Pain control is important in cancer patients. In diabetic patients, management of hypoglycemia is of utmost importance to avoid hypoglycemic shock while dental treatment. During elective dental procedures, control of blood pressure, anxiety and pain is of great concern in hypertensive patients to avoid complications like risk of cardio-vascular accident and uncontrolled bleeding. All staff members of a dental clinic must be trained for the emergencies. Dentists and their team members must be certified with Basic cardiopulmonary resuscitation (CPR) as a primary requisite. ${ }^{8}$ Apparently healthy patients may suffer from severe medical problems. It is the duty of dentists to treat such patients without any systemic complications. ${ }^{4}$

The purpose of this study is to determine the frequency of systemic diseases in dental patients presenting to tertiary care hospitals with a history form specificallydesigned to record medical conditions. Frequency of medical co-morbidities in this present study was $32.8 \%$. Epidemiological data shows the prevalence of medically compromised conditions in dental patients of northern India was $26.5 \% .{ }^{2}$ Fernández-Feijoo et al., revealed the prevalence of systemic diseases $35.2 \%$ in the public system and $28.1 \%$ in the private system at Santiago de Compostela, Galicia,
Spain. ${ }^{3}$ In the survey of Netherlands, prevalence reported was $28.2 \%{ }^{4}$ Umino et al., reported $64.2 \%$ prevalence of one or more medically compromised conditions in elderly Japanese dental patients. ${ }^{14}$ Nery et al., also detected high prevalence of systemic diseases in dental patients i.e.27.6\% in private office group, $46.3 \%$ in academic dental center and $74.1 \%$ in hospital dental clinic. ${ }^{15}$

In this study, highest frequency reported for hypertension was $28.9 \%$. Fernández-Feijoo et al., found $29.2 \%$ of dental patients as Hypertensive. ${ }^{16}$ Maryam A et al., reported $73.3 \%$ medical co-morbidities in Patients of Mashhad, out of which highest frequency was $34.1 \%$ for cardiovascular diseases. ${ }^{17}$ Dilhan Ilguy et al.,revealed percentage of hepatitis history $7.9 \% .^{5}$ In our study, hepatitis $\mathrm{C}$ accounted for $15.8 \%$ and hepatitis B for $10.5 \%$. The result of study conducted on Pakistan population should prevalence of known diabetes 1.8-4.5\%, hypertension $6.4-7.6 \%$, and ischaemic heart disease $06-1.9 \% .^{18}$

In the literature, studies have shown that the frequency of systemic disorders in dental patients has significant value.$^{19,20}$ Local study showed that there is critical requirement of for structural training of basic life support. ${ }^{21}$ The directions to get such training should be included with more emphasis organizational bodies like Pakistan Medical Comission (PMC), Healthcare Commission and Government Health Services department. Results of this study confirm the significance of medical co-morbidities in dental practice. It is the demand of present day, to have dental surgeons with enough knowledge and skills, so they can manage complications and cope up any emergency during dental procedures due to the co-morbid conditions.

\section{CONCLUSION}

This study concludes that presentation of medically compromised patients in dentistry is inevitable. Proper assessment of co-morbid conditions, in relation with dental procedure and pre or post medication, is a basic necessity. In terms of in-depth evaluation of medical conditions, a dentist must have strong background knowledge of medical conditions and related medications before operating any dental treatment.

\section{CONFLICT OF INTEREST}

None declared

\section{REFERENCES}

1. Chen H, Moeller J, and Manski RJ, The influence of comorbidity and other health measures on dental and medical care use among 
Medicare beneficiaries 2002. J Public Health Dent 2011;71:202-11. https://doi.org/10.1111/j.1752-7325.2011.00251.x

2. Walia IS, Bhatia L, Singh A, Kaur K, Duggal A. Prevalence of Medical Comorbidities in Dental Patients. AnnInt MedDen Res 2017;3:21.

https://doi.org/10.21276/aimdr.2017.3.1.DE7

3. Fernández-Feijoo J, Garea-Goris R,Fernández-Varela M, TomasCarmona I, Diniz-Freitaz M, Limeres-Posse J.Prevalence of systemic diseases among patients requesting dental consultation in the public and private systems. Med Oral Patol Oral Cir Bucal 2012;17: e89. https://doi.org/10.4317/medoral.17313

4. Smeets EC, de Jong KJ, Abraham-Inpijn L. Detecting the Medically Compromised Patients in Dentistry by Means of a Medical RiskRelated History: A Survey of 29,424 Dental Patients in the Netherlands. Prev Med 1998;27:530-5.

https://doi.org/10.1006/pmed.1998.0285

5. Ilguy D, Ilguy M, Dincer S, Bayirli G. Prevalence of the patients with history of hepatitis in a dental faculty. Med Oral Patol Oral Cir Bucal 2006;11:29-32.

6. Chandler-Gutierrez L, Martinez-Sahuquillo A, Bullon-Fernández P. Evaluation of medical risk in dental practice through using the EMRRH questionnaire. Med Oral 2004;9:309-20.

7. Ide K, Seto K, Usui T, Tanaka S, Kawakami K. Correlation between dental conditions and comorbidities in an elderly Japanese population: A cross-sectional study. Med 2018;97:e11075.

https://doi.org/10.1097/MD.0000000000011075

8. Scully C, Ettinger RL. The influence of systemic diseases on oral health care in older adults. J Am Dent Assoc 2007;138: S7-14. https://doi.org/10.14219/jada.archive.2007.0359

9. Walia IS, Bhatia L, Singh A, Kaur K, Duggal A. Prevalence of Medical Comorbidities in Dental Patients. Ann Inter Med Dent Res. 2017;3:21.

https://doi.org/10.21276/aimdr.2017.3.1.DE7

10. Burris JL, Evans DR, Carlson CR. Psychological correlates of medical comorbidities in patients with temporomandibular disorders. J Am Dent Assoc. 2010;141:22-31.

https://doi.org/10.14219/jada.archive.2010.0017

11. Allareddy V, Rampa S, Lee MK, Allareddy V, Nalliah RP. Hospitalbased emergency department visits involving dental conditions: profile and predictors of poor outcomes and resource utilization. J Am Dent
Assoc. 2014;145:331-7.

https://doi.org/10.14219/jada.2014.7

12. Allareddy V, Kim MK, Kim S, Allareddy V, Gajendrareddy P, Karimbux NY, Nalliah RP. Hospitalizations primarily attributed to dental conditions in the United States in 2008. Oral Sur, Oral Med, Oral Path Oral Rad. 2012;114:333-37. https://doi.org/10.1016/j.oooo.2012.03.024

13. Hassan SH, Shah I, Azhar M, Farooq M, Maqsood M, Mubeen T. Management of medical emergencies in dental practices-An audit. Pak Armed For Med J. 2011;95.

14. Umino M, Nagao M. Systemic diseases in elderly dental patients. Int Dent J 1993;43:213-18.

15. Nery EB, Meister Jr F, Ellinger RF, Eslami A, McNamara TJ. Prevalence of medical problems in periodontal patients obtained from three different populations. J Periodontol 1987;58:564-68. https://doi.org/10.1902/jop.1987.58.8.564

16. Fernández-Feijoo J, Nunez-Orjales J.L, Limeres-Posse J, PerezSerrano E, Tomas-Carmona I. Screening for hypertension in a primary care dental clinic. Med Oral Patol Oral Cir Bucal 2010;15: e467-72. https://doi.org/10.4317/medoral.15.e467

17. Maryam A, Atessa P, Pegah MM, Zahra S, Hanieh G, Davood A, Yeganeh K. Medical risk assessment in patients referred to dental clinics, Mashhad, Iran (2011-2012). Open Dent J. 2015;9:420. https://doi.org/10.2174/1874210601509010420

18. Claramunt Lozano A, Sarrion Perez MG, Gavalda Esteve C. Dental Management in patients with hemostasis alteration. J Clin Exp Dent 2011;3:e120-6.

https://doi.org/10.4317/jced.3.e120

19. Hameed K, Kadir M, Gibson T, Sultana S, Fatima Z, Syed A. The frequency of known diabetes, hypertension and ischaemic heart disease in affluent and poor urban populations of Karachi, Pakistan. Diabetic Med. 1995;12:500-3. https://doi.org/10.1111/j.1464-5491.1995.tb00531.x

20. Amjad A, Lahooti RA, Abassi MS. Knowledge of basic life support (BLS) amongst dental practitioners. Pak Orthod J. 2017;9:61-4.

21. Akhtar S, Rehman A, Ahmed W, Zaidi AB, Khalil O, Khan A. Knowledge, Attitude and Practices about medical emergencies among dental house officers working in two dental colleges. Pak Oral Dent J. 2019;39:133-36. 